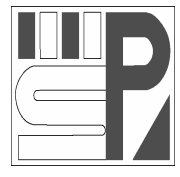

Science Press
Journal of Arid Land

2011, 3(4): 231-239

doi: 10.3724/SP.J.1227.2011.00231

jal.xjegi.com; www.chinasciencejournal.com

\title{
Breeding system and its consequence on fruit set of a rare sand dune shrub Eremosparton songoricum (Fabaceae: Papilionoideae): implications for conservation
}

\author{
DaoYuan ZHANG ${ }^{1,2^{*}}$, Xiang SHI ${ }^{3}$, JianCheng WANG ${ }^{1,2}$, HuiLiang LIU $^{1,2}$, John F GASKIN ${ }^{4}$ \\ ${ }^{1}$ Key Laboratory of Biogeography and Bioresources in Arid Land, Xinjiang Institute of Ecology and Geography, Chinese \\ Academy of Sciences, Urumqi 830011, China; \\ ${ }^{2}$ Turpan Eremophytes Botanical Garden, Chinese Academy of Sciences, Turpan 838008, China; \\ ${ }^{3}$ Forestry College, College of Agriculture in Shihezi University, Shihezi 832011, China; \\ ${ }^{4}$ USDA Agricultural Research Service, Sidney, Montana 59270, USA
}

\begin{abstract}
The breeding system and its consequence on fruit set of Eremosparton songoricum (Litv.) Vass., a rare shrubby legume occurring in moving or semi-fixed sand dunes of Central Asian deserts, were examined by manipulative experiments and observational studies in natural populations during the period of 2007-2009. The results showed that $E$. songoricum exhibits a mixed mating system. It is self-compatible, but depends strictly on pollinators to set fruits. Only two effective pollinators were detected and they triggered the specialized pollination mechanism (a 'brush type' and 'tripping mechanism'). Geitonogamy becomes predominant in natural populations, because $(74.5 \pm 1.3) \%$ of visiting activity happened within or between inflorescences and $(24.3 \pm 1.4) \%$ occurred between ramets. As a result, inbreeding depression caused by geitonogamous selfing inevitably happened under natural conditions, showing 2.36 times less fruit set than was achieved by hand cross-pollination. The results explained the rarity of the species due to its breeding system, and will assist to develop suitable conservation strategies in severe desert environments.
\end{abstract}

Keywords: geitonogamy; inbreeding depression; inland sand dunes; self-fertilization; pollen brush; tripping mechanism

Rare species, the coincidence of diversity hotspots and conservation strategies, have been considered more and more importance in the last 20 years (Prendergast, 1993; Lavergne et al., 2005). Many factors are vital to conserve rare species. The considerations in designing rare plant conservation strategies are generally concerned with the loss of genetic diversity and how this loss affects persistence of small populations (Marcella, 1993). Breeding systems will significantly influence genetic diversity within and among populations (Godt and Hamrick, 1989). The initial step in the design of a rare species' management strategy is to identify the breeding system (Hamrick et al., 1992). In flowering plants, a highly diverse array of breeding systems have evolved, varying from obligated cross-fertilization to obligated or promoted self-fertilization, with each strategy presenting selective advantages and disadvantages (Takebayashi and Morrell, 2001). In rare species, these patterns manifest special importance as they will operate in a reduced number of individual populations, primarily determining their reproductive success and secondarily affecting their population dynamics and genetic diversity (Lammi et al., 1999).

In self-compatible species, the spatial and temporal separations of male and female functions both increase the probability of out-crossing (Nair et al., 2004). The

Received 2011-04-20; accepted 2011-06-24

*Corresponding author: DaoYuan ZHANG (E-mail: daoyuanzhang@163.net) 
proximity of pollen to the receptive stigma facilitates autonomous selfing (Nair et al., 2004), while facilitated selfing may be high in plants with many inflorescences and where both the male and female organs are mature, as pollinators may forage amongst more flowers within an individual plant (Harder and Barrett, 1995). However, a major negative consequence of selfing is inbreeding depression (Young et al., 1996; Yang et al., 2005). Inbreeding depression is a dynamic feature of populations that evolved with reproductive systems, and is a powerful selective force for maintaining out-crossing in natural populations (Jarne and Charlesworth, 1993). Inbreeding can vary across the stages of the whole life history, and the population impacts of inbreeding depression may vary depending on which life history stage is most negatively affected (Kittelson and Maron, 2000). Researchers have revealed that inbreeding depression will decrease fruit set of selfed progeny compared to outcrossed progeny (Eckert, 2000).

Eremosparton songoricum (Litv.) Vass. is a rare, dwarf shrubby legume occurring in severely wind eroded moving and semi-moving sand dunes of the Gurbantunggut Desert, Xinjiang, China (Chen et al., 1983; Zhang and Hai, 2002; Yin et al., 2006), and sand dunes around Lake Balkash in Kazakstan (Vasipchenko, 1941). E. songoricum belongs to the genus Eremosparton, tribe Galegeae in the Papilionoideae. An individual can produce 100-3,000 flowers based on plant size (Zhang et al., 2008), however, this species presents a lower fruit set $(<16 \%$; Zhang et al., 2008) than most self-compatible hermaphroditic species (e.g. 72\%; Sutherland and Delph, 1984) as well as a lower seed set $(<16 \%$; Zhang et al., 2008) than most hermaphroditic species (e.g. 50\%-85\%; Charlesworth, 1989). Moreover, the seed germination rate in the wild was lower than $3 \%$ and the seedling establishment rate was lower than $0.1 \%$ (Zhang et al., 2008). Those seemed to indicate that some weaknesses existed in the sexual reproductive cycle. Besides, the distribution area of E. songoricum is fragmented, and the population size has greatly decreased during the past 50 years (Zhang et al., 2008). With the decreasing population size, selfing rates can be high and embryos suffer from reduced fitness (Ellstram and Ellam, 1993). However, till now, the breeding system, core content on reproductive success of a rare species, had not been re- ported for E. songoricum, and its consequence on fruit set is also still unclear. Under these circumstances, the elucidation of the breeding system and its consequences on reproductive success of such a rare sand dune shrub as E. songoricum has become much more importance.

The main objectives of this study were: (1) to examine the mating system of E. songoricum; (2) to check for the existence of specialized pollen release and reception mechanisms which affect the breeding procedure; and (3) to evaluate the influence of pollinators on reproductive success in a desert habitat. In conclusion, the implications for the conservation of $E$. songoricum are discussed. The research aims to shine light on the cause of weakness in sexual reproduction, and to provide useful information and new understanding of the causes of rarity of E. songoricum.

\section{Materials and methods}

\subsection{Study area and materials}

The study was conducted in a population with the area of $280 \mathrm{~m} \times 30 \mathrm{~m}$ located in the northern part of the Gurbantunggut Desert $\left(46^{\circ} 31^{\prime} 05^{\prime \prime} \mathrm{N}, 88^{\circ} 33^{\prime} 04^{\prime \prime} \mathrm{E}\right)$. The Gurbantunggut Desert is situated in the center of the Junggar Basin, Xinjiang Uygur autonomous region of China, and is the second largest desert in China with an area of $48.8 \times 10^{3} \mathrm{~km}^{2}$. Because of the "blocking effect" of the Himalayan Range, moist air currents from the Indian Ocean fail to reach the Gurbantunggut Desert, and it is far from the Pacific and the Arctic Oceans, resulting in a vast expanse of arid terrain. The mean annual precipitation is approximately $79.5 \mathrm{~mm}$, and the mean annual evaporation is $2,606.6 \mathrm{~mm}$. The average temperature is $7.26^{\circ} \mathrm{C}$ (Zhang et al., 2006). The duration of florescence of E. songoricum is about 21-26 d from late May to late June. Flowering was acropetal, starting with the basal flowers on the lowest raceme. The duration from the budding of a single flower to its withering was $6-8 \mathrm{~d}$. The flower is typically papilionaceous, comprising of a standard petal, two wing petals and a keel made up of two marginally fused petals. According to flower morphology and anther dehiscence, the typical single flowering process can be divided into four periods: pre-dehiscence, initial dehiscence, full dehiscence and flower withering (Ma et al., 2008). The length of the stamen filament 
was consistently shorter than the length of the pistil $(65 \%)$ at pre- and initial dehiscence stages, almost the same $(15 \%)$ or slightly longer $(20 \%)$ at fulldehiscence stage, and then shorter again at flower withering stage (Ma et al., 2008). The duration of the fruiting period is from mid July to late August. Our field investigation and lab experiments were conducted from 2007 to 2009.

\subsection{Stigma receptivity, stigmatic cuticle test and stigma ultra-structure}

We randomly selected 60 flower buds under natural condition. Five stigmas were tested with a $1 \%$ solution of the 2, 5-diphenyl tetrazolium bromide (MTT) in 5\% sucrose every $12 \mathrm{~h}$ from the very beginning of flowering (the experiments lasted 6 days). The stigma was considered receptive when the surface turned dark purple under a dissecting microscope, and non receptive if there was a lack of color change.

The presence of the stigmatic cuticle was tested through experiments with Neutral Red and optical microscopy (Heslop-Harrison and Heslop-Harrison, 1982) on stigmas excised under three conditions: (1) intact flower buds ( $n=10),(2)$ flower buds in which stigmas were touched with a paint-brush $(n=10)$, and (3) open mature flowers which had been visited by insects according to field observation $(n=10)$. If stigma surface appeared red colored only after it was ruptured due to mechanical disturbance (as second condition) or flower tripping (as third condition), it meant that a cuticle was present.

Another 30 flowers under the three conditions mentioned above ( $n=10$ for each condition) were fixed in FAA solution (formalin (40\%), acetic acid and alcohol (70\%) at a ratio of 5:6:89 by volume), followed by dehydration in a graded ethanol series $(70 \%, 80 \%$, $90 \%, 95 \%$ and twice in $100 \%$ concentration for 15 min). Then, the stigmas were excised from the flowers. Such critical point drying was necessary to avoid the collapse of the stigmas before coating with gold. Stigmas were examined using a scanning electron microscope (Leo 1430VP, Leo company, US).

\subsection{Breeding system}

In order to determine whether or not E. songoricum obligately requires pollinators to set seed, five randomly chosen individual plants were bagged before flowers opened and fertile fruit were scored 5-7 weeks after treatment. The mating system was investigated following the method of Dafni (2005). Five experiments were designed as follows: (1) autonomous self-pollination-buds were bagged throughout their flowering period; (2) apomixis-anthers of bagged buds were emasculated; (3) hand self-pollinationbagged buds were self-pollinated by hand with pollen within the flower immediately after anthesis; (4) hand geitonogamous-pollination-bagged and emasculated buds were geitonogamous-pollinated by hand with pollen from the same individuals; and (5) hand outcross-pollination-bagged and emasculated buds were pollinated by hand with pollen of recently opened flowers of other clones ( $>10 \mathrm{~m}$ away). For each experiment, three flowers were chosen from each of the five individuals, for a total of three replications. All the emasculation treatments were performed before anther dehiscence.

In addition, fruit set and seed set under natural pollination were estimated. Ten flowering inflorescences with 1,453 flowers were randomly chosen. According to field investigation, many young pods will be abscised and fall down eventually (unpublished observation, Shi, 2006). Garwood and Horvitz (1985) showed that ovary enlargement was a valid criterion for assessing fertilization of ovules. On this basis, the number of fruits with embryos was recorded at the beginning expansion (phase I), and at the stage when the fruit was completely matured (phase II). Fruit set for each plant, which equals the total number of fruits divided by the total number of flowers, was calculated at both phase I and phase II. Seed set was defined as the proportion of ovules that developed into seeds in all the mature fruits within an inflorescence.

A self compatibility index (SCI) was estimated as the ratio between fruit set obtained by hand self-pollination and that obtained by hand cross-pollination (Etcheverry et al., 2008). When SCI was $<0.2$, the population was considered to be self-incompatible (Arroyo and Uslar, 1993). The relative reproductive success (RRS) of an inflorescence was calculated by multiplying fruit set by seed set (Kasagi and Kudo, 2003).

\subsection{Pollinators and foraging behavior}

In order to identify the effective pollinators and major pollination mode, we observed the pollinators and recorded the foraging behavior within and between indi- 
viduals in 2007. This observation had 30 replications (Zhang, 2006). The captured insects were sampled for pollen types by touching fuchsin gel to the insect's body (Liu and Koptur, 2003). The gel was then melted onto a slide for examination under an optical microscope with $100 \times$ optical magnification. The pollinators which carried the pollen of E. songoricum and contacted with the stigma, resulting in pollination, were considered as effective pollinators in the wild population. At least five individuals of each species of effective pollinator were collected for identification in Xinjiang University.

\subsection{Data analysis}

The results were analyzed using SPSS 16.0 software, and the figures were made with Excel 2003. The data were described by mean \pm SE. Tukey-HSD method of one way ANOVA was performed in order to compare the fruit set between fertilization treatments in phase I and phase II. The other variations were compared by Independent Sample T-Tests. Data normality was comprehensively considered by Kolmogorov-Smimov and Shapiro-Wilk Indices. The Levene test was used for homogeneity of variance test.

\section{Results}

\subsection{Stigma receptivity, stigmatic cuticle mem- brane and stigma ultra-structure}

E. songoricum shows protogyny. The stigma receptivity lasts about $6 \mathrm{~d}$ from the end of the pre-dehiscence stage to flower withering stage. The time of stigma receptivity overlaps the time of anther dehiscence.

Staining experiments showed that stigmas excised from mature open flowers and stigmas touched with a tiny paint-brush were permeable to the dye and stained to red color, while stigmas excised from intact flower buds did not change color and showed high impermeability, indicating the presence of a cuticle membrane. In addition, when observed under a scanning electron microscope, intact buds showed no germinating pollen grains on their stigma (Fig. 1b), while mature flowers (Fig. 1c) and flower buds touched by a tiny paint-brush (Fig. 1e) showed the presence of germinating pollen grains. This means that the pollen could germinate only when the stigma cuticle membrane was disrupted by tripping and the stigmatic fluid flowed out (Fig. 1d). So, the presence of a stigmatic cuticle membrane is proved. The cuticle could be tripped only by insects or by mechanical disruption before they accepted pollen germination, demonstrating a similar 'tripping mechanism' as recorded in other legumes.

When the ultra-structure of stigma of $E$. songoricum was observed under a scanning electron microscope, it showed that the stigma was surrounded by a dense aggregation of erect trichomes (Fig. 1a, b), representing the 'pollen brush' morphology just as re-defined by Lavin and Delgado (1990). Pollen released from anthers was trapped between the trichomes of the stylar brush (Fig. 1f).

\subsection{Breeding system}

Five individuals, bagged early to exclude insects, did not set fruit, indicating that the reproduction of the species depends on insect pollination. After pollination by hand with autogamous, geitonogamous and outcross pollen, the fruit set in phase I showed no significant difference (Table 1), indicating high self-compatibility of E. songoricum. Furthermore, the SCI index was $0.54(>0.2)$, confirming that $E$. songoricum is self-compatible.

The results of the mating system experiments are presented in Table 1. None of the flowers set fruit in the apomixis treatment, indicating that apomixis does not occur. In the autonomous self-pollination treatments, only $8.90 \%$ of fruit set was observed in phase I and $0.01 \%$ in phase II, indicating that autonomous autogamy rarely occurs. When self-pollinated by hand, relatively high fruit production (89.99\%) was observed in phase I and $16.93 \%$ in phase II (Table 1), therefore, facilitated autogamy could occur. Hand cross-pollination set 2.64 and 2.61 times more fruit in phase II than hand self-pollination and hand geitonogamous pollination respectively, which indicates that outcross pollen attributed to reproductive success. In addition, hand cross-pollination also set 2.36 times more fruits in phase II than natural pollination, which indicates that in natural populations outcross pollen is hard to deposit on stigma and set fruit.

Fruit production in phase I was significantly higher compared to phase II $(|\mathrm{t}|=31.50, \mathrm{df}=280, P<0.001)$ (Table 1) under conditions of natural pollination, which indicates that fruit abortion in E. songoricum 

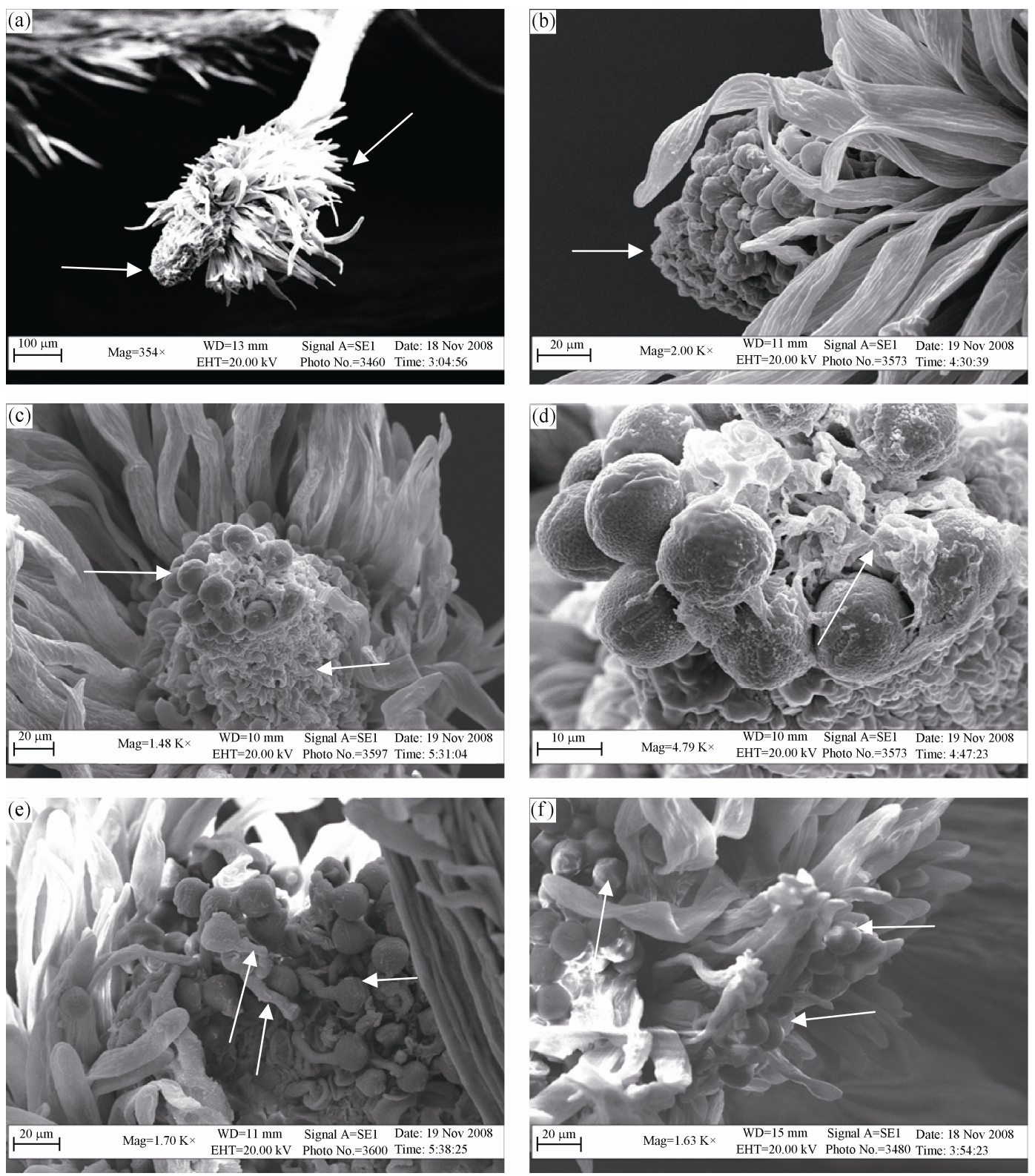

Fig. 1 SEM photomicrographs of the pollen brush of E. songoricum. (a) The morphology of stigma (right arrow) and stylar brush (left arrow); (b) An intact stigmatic surface (arrow); (c) A tripped stigmatic surface (right arrow) with germinated pollen (left arrow); (d) Stigmatic fluids appear after tripping (arrow); (e) Germinated pollen grains (right arrow) with pollen tube growth (left arrows); (f) Detail of the stylar brush, with pollen grains trapped in the trichomes (arrows).

Table 1 Fruit set (mean $\pm S E$ ) of $E$. songoricum within each treatment in different phases (lowercase letters) and between each pollination treatment (uppercase letters) in 2007

\begin{tabular}{|c|c|c|c|c|c|c|}
\hline Treatments & Natural pollination & Autonomous selfing & $\begin{array}{c}\text { Hand self-pollination } \\
(\%)\end{array}$ & $\begin{array}{l}\text { Hand geitonogamous } \\
\text { Pollination }\end{array}$ & $\begin{array}{l}\text { Hand outcross } \\
\text { Pollination }\end{array}$ & Apomixis \\
\hline \multirow{2}{*}{$\begin{array}{l}\text { Phase I } \\
\text { Phase II }\end{array}$} & $\begin{array}{c}88.61 \pm 3.31^{\mathrm{a}, \mathrm{A}} \\
(n=1453)\end{array}$ & $\begin{array}{c}8.90 \pm 0.85^{\mathrm{a}, \mathrm{B}} \\
(n=90)\end{array}$ & $\begin{array}{c}89.99 \pm 1.20^{\mathrm{a}, \mathrm{A}} \\
(n=88)\end{array}$ & $\begin{array}{c}88.56 \pm 2.17^{\mathrm{a}, \mathrm{A}} \\
(n=89)\end{array}$ & $\begin{array}{c}88.55 \pm 2.52^{\mathrm{a}, \mathrm{A}} \\
(n=90)\end{array}$ & $\begin{array}{c}0^{\mathrm{a}, \mathrm{C}} \\
(n=90)\end{array}$ \\
\hline & $\begin{array}{c}14.47 \pm 1.20^{\mathrm{b}, \mathrm{B}} \\
(n=1453)\end{array}$ & $\begin{array}{c}0.01 \pm 0.02^{\mathrm{a}, \mathrm{C}} \\
(n=90)\end{array}$ & $\begin{array}{c}12.93 \pm 1.28^{\mathrm{b}, \mathrm{B}} \\
(n=88)\end{array}$ & $\begin{array}{c}13.05 \pm 0.32^{\mathrm{b}, \mathrm{B}} \\
(n=89)\end{array}$ & $\begin{array}{c}34.10 \pm 1.31^{\mathrm{b}, \mathrm{A}} \\
(n=90)\end{array}$ & $\begin{array}{c}0^{\mathrm{a}, \mathrm{C}} \\
(n=90)\end{array}$ \\
\hline
\end{tabular}

Note: Phase I means the time when the fruit is beginning expansion, and phase II means the time when the fruit is completely mature; ' $n$ ' $=$ the number of total manipulated flowers in each treatment. The different lowercase and uppercase letters show significant difference at 0.01 level. 
can be frequent, and about $70 \%$ of fruits were aborted during fruit development, between pollination and fruit maturation. We also noticed that seed production $(1.01 \pm 0.01)$ was much lower than ovules per ovary $(8.33 \pm 0.19) \quad(|\mathrm{t}|=119.10, \quad \mathrm{df}=463, \quad P<0.001)$, which means that some ovules were not fertilized and/or they were aborted early in fruit development. The index of RRS equaled 0.019 .

\subsection{Pollinators and foraging behavior}

Only two visitors were recorded as effective pollinators. The most frequent pollinator was Megachile terminat Morawitz, accounting for $89.3 \%$ of all the visits. Another was one species from the Stenogastridae family which need to be further identified. They all used their middle leg and rear leg to grasp the projecting part of the flower wing, and then opened the keel with their fore legs so as to introduce their proboscis between keel and vexillum to obtain nectar. Keel petals were always enclosed during all the flowering process until the flower was visited by a pollinator. When visited by a pollinator, the style with a pollen-loaded brush was forced through the keel tip and the pollen was brushed on the visitor.

Based on the observation of 30 individuals of $M$. terminat, $(74.5 \pm 1.3) \%$ of visiting activity happened within or between inflorescences of the same individual plant, and (24.3 \pm 1.4$) \%$ occurred between different ramets.

\section{Discussion}

\subsection{Breeding system and its consequence on fruit-set}

The results of this study indicate that E. songoricum exhibits a mixed mating system. E. songoricum is self-compatible, but depends strictly on pollinators to set fruits. Autonomous selfing rarely happens. Two structural features are related to this phenomenon: the stigmatic cuticle membrane and the pollen brush structure. The stigmatic membrane prevents autonomous self-pollination, and as a consequence $E$. songoricum requires tripping for effective pollination. This membrane was reported to be present in seven tribes of Papilionoideae (Shivanna and Owens, 1989). Pollen did not germinate until the stigmatic cuticle membrane was disrupted and lipid-rich secretions hydrated the pollen (Lord and Harrison, 1984; Britten and Dunda, 1985; Castro and Agulló, 1998). In E. songoricum, only tripping by insects (Fig. 1c) or manual tripping (Fig. 1e) could result in the rupture of the stigmatic membrane and facilitate pollen germination. Another structural feature, a pollen brush, may prevent autonomous selfing and may maximize out-crossing of E. songoricum by preventing self-pollen deposition on the stigmas during anthesis. The erect trichomes emanating from the style are an essential feature of the pollen brush in that they enable pollen to be brushed upward and trapped (Fig. 1f), and then brushed onto the visiting pollinators, showing a secondary pollen presentation mechanism (Lavin and Delgado, 1990). Polhill (1976) suggested that the pollen brush confers an economy of pollen transfer to the individual flower. In our artificial self-pollination experiment, the pollen was rubbed on the stigma with a brush. This may be the reason why greater fruit sets were seen on these flowers compared with the unmanipulated (autonomous selfing) flowers.

The pattern of mating in populations depends on complex interactions between the agents that move pollen from anther to stigmas, as well as many aspects of floral biology, growth form, and population structure (Eckert, 2000). In E. songoricum, the combination of self-compatibility, modular growth, clonal propagation and mass-flowering provides manifold opportunities for geitonogamy. Regarding the behavior of the effective pollinator, Megachile terminat Morawitz, (74.5 \pm 1.3$) \%$ of visiting activity happened within individuals and $(24.3 \pm 1.4) \%$ of foraging behavior occurred between ramets, indicating that geitonogamy frequently happens in natural populations. In addition, we found that foraging behavior occurring between ramets may be restricted between ramets of the same clone, since E. songoricum has identical clonal structure between neighbor ramets $(<7 \mathrm{~m})$ when detected by ISSR (Inter Simple Sequence Repeat) markers (Lu et al., 2007; Liu et al., 2010). Consequently, geitonogamy is the predominant mating mode in E. songoricum.

Lloyd and Schoen (1992) concluded that families characterized by specialized pollination mechanisms, such as papilionoideae, have undergone natural selection promoting cross-pollination. In fact, the ratio pollen to ovule for $E$. songoricum was (1,255 \pm 139$)$ : 1 (Ma, 2007), which indicates that the species is out-crossing with a tendency towards facultative out-crossing according to the criteria of Cruden (1977). In this study, hand cross-pollination of E. songoricum produced 
significantly higher numbers of fruits in phase II than hand self and geitonogamous pollination respectively, showing out-cross pollination is greatly beneficial to fruit set. Compared to open pollination, hand cross-pollination set more than twice the number of fruits, implying that out-cross pollination seldom happens in natural conditions, maybe due to pollinator limitations. We consider that, although natural selection promotes cross-pollination, E. songoricum exerts geitonogamy more often, as an unavoidable consequence of simultaneous multi-flowering and clonal propagation.

However, geitonogamy is disadvantageous, probably resulting in severe pollen and seed discounting and provides little reproductive assurance (Lloyd, 1992; Eckert, 2000). In addition, geitonogamy will lead to self-fertilization and may cause inbreeding depression in self-compatible species (Young et al., 1996; Yang et al., 2005). In this study, artificial self-pollination and geitonogamy decreased fruit set (phase II) compared with that of hand out-cross pollination. The results indicate that inbreeding depression plays a role during the period from fertilization to fruit maturation, as reported in another Fabaceae species (Lupinus arboreus) (Pamela and John, 2000). Furthermore, geitonogamy of clonal plants is always coupled with strong inbreeding depression (Eckert and Barrett, 1994). Consequently, geitonogamy is inevitable in $E$. songoricum and brings strong inbreeding depression, which seems to be disadvantageous in E. songoricum.

Extremely low reproductive success (0.019) was observed in E. songoricum compared to other Papilionoideae species (Etcheverry et al., 2008). Low reproductive success seems to be a general phenomenon in $E$. songoricum with low fruit and seed production.

\subsection{Conservation implications}

Geitonogamy inevitably leads to strong breeding de-

\section{References}

Arroyo M T K, Uslar P. 1993. Breeding systems in temperate Mediterranean-type climate montane sclerophyllous forest in central Chile. Botanical Journal of Linnean Society, 111(1): 83-102.

Britten E J, Dundas I S. 1985. A dimorphic pollination system in a potentially valuable semi-arid pasture legume the Psoralea patens complex. In: Proceedings of the $15^{\text {th }}$ International Grassland Congress. Kyoto, Japan. Kyoto: Science Council of Japan and Japan Society of Grassland Science, 209-210.

Castro M A, Agulló M A. 1998. Anatomy of the stigma of Vigna adenan- pression in E. songoricum, especially in small and isolated populations. In the Gurbantunggut Desert, ecosystems have suffered a massive reduction in size and quality as a consequence of the engineering activities related to oil-gas extraction in the past 60 years (Qian et al., 2002). These activities have a great effect on E. songoricum, causing habitat fragmentation, population decline and strong genetic differentiation among populations because of limited gene flow ( $\mathrm{Lu}$ et al., 2007; Zhang et al., 2008). In addition, inbreeding depression is typically greater in more stressful environments (Parsons, 1971; Jiminez et al., 1994; David et al., 2002). As a result, stress may increase extinction risk due to inbreeding. Thus, the preservation of habitat and the maintenance of populations are most important in any strategy aimed at conservation of E. songoricum, and more generally, of the Gurbantunggut Desert flora and fauna.

E. songoricum depends strictly on pollinators to set fruits. As a result, protections of wild bee populations or developing apiculture in this area are likely to be the most effective strategies for maintaining the existing natural plant populations. In addition, out-cross pollination contributed to reproductive success, but seldom is out-cross pollen deposited on stigma in natural populations. Therefore, it maybe helpful to undertake artificial out-cross pollination activities in natural, or even in ex-situ protected populations, with a minimum distance of seven meters between plants or groups of plants to avoid geitonogamous pollination between ramets.

\section{Acknowledgments}

This work was supported by the National Natural Science Foundation of China (30970547, 31070472) and the National Basic Research Program of China (2009CB825104).

tha (C.F.Mayer) Marechal, Mascherpa and Stainer (Leguminosae, Papilionoideae). Biocell, 22: 9-18.

Charlesworth D. 1989. Evolution of low female fertility in plants: pollen limitation, resource allocation and genetic load. Trends in Ecology and Evolution, 4(10): 289-292.

Chen C D, Zhang L Y, Hu W K. 1983. The basic characteristics of plant communities, flora and their distribution in the sandy district of Gurbantunggut Desert. Acta Phytoecologica et Geobotanica Sinica, 7(2): 89-99. 
Cruden R W. 1977. Pollen-ovule ratios: a conservative indicator of breeding systems in flowering plants. Evolution, 31(1): 32-46.

David H R, David A B, Richard F. 2002. Inbreeding and extinction: the effect of environmental stress and lineage. Conservation Genetics, 3(3): 301-307.

Eckert C G, Barrett S C H. 1994. Inbreeding depression in partially self-fertilizing Decodon verticillatus (Lythraceae): population genetics and experimental analyses. Evolution, 48(4): 952-964.

Eckert C G. 2000. Contributions of autogamy and geitonogamy to self-fertilization in a mass-flowering, clonal plant. Ecology, 81: 532-542.

Ellstram N C, Ellam D R. 1993. Population genetic consequences of small population size: implications for plant conservation. Annual Review of Ecology System, 24: 217-241.

Etcheverry A V. Alemán M M, Fleming T F. 2008. Flower morphology, pollination biology and mating system of the complex flower of Vigna caracalla (Fabaceae: Papilionoideae). Annals of Botany, 102(3): 305-316.

Garwood N C, Horvitz C C. 1985. Factors limiting fruit and seed production of a temperate shrub, Staphylea trifolia L. (Staphyleaceae). American Journal of Botany, 72(3): 453-466.

Harder L D, Barrett S C H. 1995. Mating cost of large floral displays in hermaphrodite plants. Nature, 373: 512-515

Hamrick J L, Godt M J W. 1989. Allozyme diversity in plant species. In: Brown A H D, Clegg M T, Kahler A L, et al. Plant Population Genetics, Breeding and Genetic Resources. Sunderland, Mass: Sinauer Press, 43-63.

Hamrick J L, Godt M J W. 1992. Factors influencing levels of genetic diversity in woody plant species. New Forest, 6(1-4): 95-124.

Heslop-Harrison J, Heslop-Harrison Y. 1982. Pollen-stigma interaction in the Leguminosae: constituents of the stylar fluid and stigma secretion of Trifolium pretense L. Annals of Botany, 49(6): 729-735.

Jarne P, Charlesworth D. 1993. The evolution of the selfing rate in functionally hermaphrodite plants and animals. Annual Review of Ecology and Systematics, 24: 441-466.

Jiminez J, Hughes K, Alaks G, et al. 1994. An experimental study of inbreeding depression in a natural habitat. Science, 266(5183): 271-273.

Kasagi T, Kudo G. 2003. Variations in bumble bee preference and pollen limitation among neighboring populations: comparisons between Phyllodoce caerulea and P. aleutica (Ericaceae) along snowmelt gradients. American Journal of Botany, 90(9): 1321-1327.

Kittelson P M, Maron J H. 2000. Outcross rate and inbreeding depression in the perennial yellow bush Lupine, Lupinus arboreus (Fabaceae). American Journal of Botany, 87: 652-660.

Lammi A, Siikamäki P, Mustajärvi K. 1999. Genetic diversity, population size, and fitness in central and peripheral populations of a rare plant Lychnis viscaria. Conservation Biology, 19(5): 1069-1078.

Lavergne S, Wilfried T, Molina J. 2005. Environmental and human factors influencing rare plant local occurrence, extinction and persistence: a 115-year study in the Mediterranean region. Journal of Biogeography, 32(5): 799-811.

Lavin M, Delgado S. 1990. Pollen brush of Papilionoideae (Leguminosae): morphological variation and systematic utility. American Journal of Botany, 77(10): 1294-1312.

Leppik E E, 1966. Floral evolution and pollination in Leguminosae. Annales Botanici Fennici, 3: 299-308.

Liu H, Koptur S. 2003. Breeding system and pollination of a narrowly endemic herb of the lower Florida Keys: impacts of the urban-wildland interface. American Journal of Botany, 90(8): 1180-1187.

Liu Y, Zhang D Y, Yang H L, et al. 2010. Fine-scale genetic structure of Eremosparton songoricum and implication for conservation. Journal of Arid Land, 2(1): 156-178.

Lloyd D G. 1992. Self- and cross-fertilization in plants. II. The selection of self-fertilization. International Journal of Plant Sciences, 153(3): $370-380$.

Lord E M, Harrison H Y. 1984. Pollen-stigma interaction in the Leguminosae: stigma organization and the breeding system in Vicia faba L. Annals of Botany, 54(6): 827-836.

Lu X Y, Zhang D Y, Ma W B. 2007. Genetic variation and clonal diversity in fragmented populations of the desert plant Eremosparton songoricum based on ISSR markers. Biodiversity Science, 15(3): 282-291.

Ma W B. 2007. Reproductive Ecology of Eremosparton songoricum. MSc Thesis. Xinjiang: Xinjiang Agricultural University.

Ma W B, Shi X, Zhang D Y, et al. 2008. Flowering phenology and reproductive features of the rare plant Eremosparton songoricum in desert zone, Xinjiang. Chinese Journal of Plant Ecology, 32(4): 760-767.

Marcella M D. 1993. Relationship of breeding system to rarity in the lakeside daisy (Hymenoxys acaulis var. glabra). Conservation Biology, 7(3): 542-550.

Nair R M, Dundas I S, Wallwork M, et al. 2004. Breeding system in a population of Trigonella balansae (Leguminosae). Annals of Botany, 94(6): 883-888.

Pamela M K, John L M. 2000. Outcrossing rate and inbreeding depression in the perennial yellow bush lupine, Lupinus arboreus (Fabaceae). American Journal of Botany, 87(5): 652-660.

Parsons P A. 1971. Extreme environment heterosis and genetic loads. Heredity, 26(3): 479-483.

Polhill R M, 1976. Genisteae (Adans.) and related tribes (Leguminosae). Botanical Systematics, 1: 143-368.

Prendergast J R, Quinn R M, Lawton J H, et al. 1993. Rare species, the coincidence of diversity hotspots and conservation strategies. Nature, 365: 335-337.

Qian Y B, Zhang L Y, Wu Z N. 2002. Damage and recovery of the Gurbantunggut Desert vegetation following engineering activities. Science in China: Series D, 45(Suppl.): 78-86.

Shivanna K R, Owens S J. 1989. Pollen pistil interactions (Papilionoideae). In: Stirton C H, Zarucchi J L. Advances in Legume Biology. Missouri: Monographs of Systematic Botany of the Missouri Botanical Garden, 29: 157-182. 
Sutherland S, Delph L. 1984. On the importance of male fitness in plants: patterns of fruit set. Ecology, 65(4): 1093-1104.

Takebayashi N, Morrell P L. 2001. Is self-fertilization an evolutionary dead end? Revisiting an old hypothesis with genetic theories and a macroevolutionary approach. American Journal of Botany, 88(7): 1143-1150

Vasipchenko. 1941. Flora of CCCP. Tomus XI. 310-311.

Yang C F, Sun S G, Guo Y H. 2005. Resource limitation and pollen source (self and outcross) affecting seed production in two louseworts, Pedicularis Siphonantha and P. longiflora (Orobanchaceae). Botanical Journal of the Linnean Society, 147(1): 83-89.

Yin L K, Tan L X, Wang B. 2006. Rare, Endangered and Endemic Higher Plants in Xinjiang of China. Urumqi: Xinjiang Scientific and Technical Publishing House, 74-75.

Young A, Boyle T, Brown T. 1996. The population genetic consequences of habitat fragmentation for plants. Trends in Ecology and Evolution, 11(10): 413-418.

Zhang D Y, Ma W B, Shi X. 2008. Distribution, and bio-ecology characteristics of Eremosparton songoricum, a rare plant in Gurbantunggut Desert. Journal of Desert Research, 28(3): 430-436.

Zhang L Y, Hai Y, 2002. Plant communities excluded in the book of "The Vegetation and Its Utilization in Xinjiang". The desert plant communities. Arid Land Geography, 25(1): 84-89.

Zhang T F, Duan Y W, Liu J Q. 2006. Pollination ecology of Aconitum gymnandrum (Ranunculaceae) at two sites with different altitudes. Acta Phytotaxonomica Sinica, 44(4): 362-370.

Zhang Y M, Wang H L, Wang X Q, et al. 2006. The microstructure of microbiotic crust and its influence on wind erosion for a sandy soil surface in the Gurbantunggut Desert of Northwestern China. Geoderma, 132(3-4): 441-449.

\section{Journal of Arid Land selected for SCIE}

On July 15, 2011, the editorial office of the Journal of Arid Land (JAL) received an e-mail transmitted through Prof. ZHU Cheng, the consultant of the Chinese Society of University Journals in Natural Sciences and the standing director of China Editology of Science Periodicals. The e-mail was sent by Mariana Boletta, the Senior Editor of Thomson Reuters, who said that JAL has been selected for coverage in Science Citation Index Expanded (SCIE) and Current Contents/Agriculture, Biology \& Environmental Sciences, beginning from the initial issue in 2009.

Launched in the fourth quarter of 2009, JAL is an international quarterly journal in the natural sciences (website: jal.xjegi.com), sponsored firstly by Xinjiang Institute of Ecology and Geography and secondly by the Science Press of Chinese Academy of Sciences, and published by Science Press. Over the past two years, JAL has actively tracked the international research hot topics in arid areas, quickly improved the quality of the journal, and raised its international impact under the great support of the directors of the Xinjiang Institute of Ecology and Geography, Chinese Academy of Sciences, and the joint efforts of the Editorial Board and the editors of JAL. Since launching in 2009, JAL has insisted on an international development path, and has encouraged international authors, while recruiting international reviewers and editorial board members. The papers published in JAL cover a broad field of environmental research and promote understanding of the characteristics of arid regions. JAL has been abstracted/indexed internationally by VINITI Abstracts Journal (PЖ) in Russia, Index of Copernicus in Poland, and Ulrich's Periodicals Directory in USA, and nationally by the Chinese Core Journals (Screening) Database and China Academic Journals Integrated Online Database. 